\title{
Influence of Deep Cryogenic Treatment on Microstructure and Properties of 7A99 Ultra-High Strength Aluminum Alloy
}

\author{
Wenlin Gao ${ }^{1,2,3}$, Xiangjie Wang ${ }^{1, *}$, Junzhou Chen ${ }^{2,3}$, Chunyan Ban ${ }^{1}$, Jianzhong Cui ${ }^{1}$ and \\ Zheng $\mathrm{Lu}^{2,3}$ \\ 1 Key Laboratory of Electromagnetic Processing of Materials, Ministry of Education, Northeastern University, \\ Shenyang 110819, China; 13241663121@163.com (W.G.); bancy@epm.neu.edu.cn (C.B.); \\ jzcui@epm.neu.edu.cn (J.C.) \\ 2 Beijing Institute of Aeronautical Materials, Beijing 100095, China; junzhouchen@126.com (J.C.); \\ luzheng621@126.com (Z.L.) \\ 3 Beijing Engineering Research Center of Advanced Aluminum Alloys and Application, Beijing 100095, China \\ * Correspondence: wangxj@epm.neu.edu.cn; Tel.: +138-4013-8216
}

Received: 30 April 2019; Accepted: 28 May 2019; Published: 31 May 2019

\begin{abstract}
The hardness, toughness, wear resistance, and fatigue behavior of materials can be improved through a deep cryogenic treatment (DCT). During this treatment, low temperatures $\left(-100{ }^{\circ} \mathrm{C}\right.$ to $-196^{\circ} \mathrm{C}$ ) are maintained and then increased to room or higher. In this work, an indirect-extrusion plate of 7A99 ultra-high strength aluminum alloy was subjected to a T6 (peak aging) treatment and a T6-DCT treatment. The influence of the T6-DCT treatment on the mechanical properties, grain morphologies, precipitates, and atom-cluster distribution was investigated via tensile testing, electron backscatter diffraction, transmission electron microscopy, and three-dimensional atom probe analysis. The tensile strength (maximum: 705 deep cryogenic treatment), yield strength (maximum: $678 \mathrm{MPa}$ ), and elongation (maximum: 14\%) of the T6-DCT-treated alloy were higher than those of the T6-treated alloy. Moreover, the T6-DCT treatment resulted in (i) grain size refinement and increased uniformity of the microstructure (homogeneous distribution of $\eta^{\prime}-\mathrm{MgZn}_{2}$ - and $\eta$-phase precipitates), and (ii) reduced segregation degree of $\mathrm{Zn}, \mathrm{Mg}$, and $\mathrm{Cu}$ atoms in the matrix (fraction of small atom clusters (sizes: 10-20 nm, 20-50 nm) increased, fraction of large clusters (size: $>1,000 \mathrm{~nm}$ ) decreased). Therefore, DCT can refine the precipitates and increase the uniformity of the precipitate distribution, thereby improving the strength and plasticity of the alloy.
\end{abstract}

Keywords: DCT; 7A99 ultra-high strength alloy; transmission electron microscopy; three-dimensional atom probe; precipitation

\section{Introduction}

In recent years, with the rapid development of weaponry, 7XXX ultra-high strength aluminum alloys have been used increasingly in military fields [1-5]. At present, the 7A85 (which exhibits excellent mechanical properties and corrosion resistance) and 7A55 alloys are extensively employed in aerospace applications. Outstanding tensile properties and stress corrosion resistance have also been reported for forged 7A85-T7452 alloy. However, the tensile strength of the 7A85 alloy is relatively low compared to that of the 7A55 alloy. The high-strength 7A55 alloy exhibits poor stress corrosion resistance due to the relatively high content of $\mathrm{Cu}$ [6-8]. 7A99 alloy, developed by Beijing Institute of Aeronautical Materials, is a new ultra-high strength and toughness aluminum alloy that has been used on a preliminary basis in weaponry. The mechanical properties and stress corrosion resistance of 7A99 are superior to those of 7A55. Materials with extremely high strength and toughness are required due 
to the harsh service environment associated with military operations. However, aging heat treatments such as T6, T73, T76, T74, T77, T78, and T79, yield inadequate strength and toughness.

Deep cryogenic treatment (DCT), a material treatment method that uses liquid nitrogen as a refrigerant for reaching temperatures below $-100{ }^{\circ} \mathrm{C}$, represents an innovative extension of traditional heat treatments. During this treatment, samples are placed in a specific, controllable, and low-temperature environment with the aim of improving the mechanical and physical properties through microstructural modification of the materials [9-13]. Recently, researchers have combined DCT with solution and aging processes of aluminum and magnesium alloys, and found that reasonable DCT processes change the microstructure and properties of these alloys. The mechanism governing the effect of DCT on these materials has also been investigated. Li et al. [14] investigated the effect of a four-time cold and thermal cycling aging treatment on 7055 aluminum alloy extrusion plates. The results revealed that the precipitate size decreases and the dislocation density increases with increasing cycle number. Chen et al. [15] subjected 12 types of aluminum alloys to 1-8 cycles of a DCT process, and found that DCT can improve the room-temperature tensile strength of 1230, 2017, 2024, 3003, 4032, 7075, and 8009 alloys. Asl et al. [16] investigated the effect of DCT on AZ91 magnesium alloy, and reported that DCT results in refinement of the $\beta$ phase and improvement of the wear resistance. Nonetheless, studies focused on the effect of DCT on the strength and toughness of 7A99 ultra-high strength and toughness aluminum alloy have rarely been reported.

In this work, an indirect-extrusion plate of a 7A99 aluminum alloy with ultra-high strength and toughness was used as the experimental material, and a DCT process was combined with solid solution and artificial aging treatments. The effect of DCT on the microstructures and mechanical properties of the alloy was determined through macroscopic analysis and microstructural characterization. The purpose of this study was to develop a new heat treatment method that yields improved properties of the 7A99 ultra-high strength and toughness aluminum alloy.

\section{Materials and Methods}

A 7A99 ingot (diameter: $540 \mathrm{~mm}$ ) was prepared via semi-continuous casting (see Table 1 for the composition of the alloy). The ingot was homogenized and extruded into a plate (cross-sectional area: $60 \mathrm{~mm} \times 300 \mathrm{~mm}$ ) on a $55 \mathrm{MN}$ indirect extrusion machine (SMS group, Dusseldorf, Germany) (see Table 2 for the extrusion parameters). After extrusion, the plate was sawed into 150-mm segments, and then subjected to T6 and T6-DCT heat treatments. The T6 heat treatment consisted of the following steps: immediately after the solid solution treatment, the samples were subjected to a 24-h artificial aging treatment at $120^{\circ} \mathrm{C}$. Similarly, the T6-DCT heat treatment consisted of the following steps (see Table 3): immediately after the solid solution treatment, the samples were subjected to DCT and then artificial aging. The samples were then cooled to room temperature in air, thereby completing a cooling and thermal cycle treatment. Two and three of these cooling and thermal cycles were subsequently performed. Afterward, the samples underwent a $24-\mathrm{h}$ artificial aging treatment at $120{ }^{\circ} \mathrm{C}$.

Table 1. Composition of the 7A99 aluminum alloy (wt.\%).

\begin{tabular}{cccccccc}
\hline $\mathbf{Z n}$ & $\mathbf{M g}$ & $\mathbf{C u}$ & $\mathbf{Z r}$ & $\mathbf{T i}$ & $\mathbf{F e}$ & $\mathrm{Si}$ & $\mathbf{B e}$ \\
\hline $7.6-8.6$ & $1.7-2.5$ & $1.4-2.0$ & $0.1-0.20$ & $0.02-0.05$ & $\leq 0.08$ & $\leq 0.06$ & $\leq 0.002$ \\
\hline
\end{tabular}

Table 2. Parameters of the indirect extrusion process $\left(T_{m}\right.$, Mold temperature; $T_{P}$, Preheat temperature; $T_{\mathrm{C}}$, Container temperature; $\lambda$, Extrusion ratio; and $V_{S}$, Extrusion velocity).

\begin{tabular}{ccccc}
\hline$T_{m} /{ }^{\circ} \mathbf{C}$ & $T_{p} /{ }^{\circ} \mathbf{C}$ & $T_{c} /{ }^{\circ} \mathbf{C}$ & $\lambda$ & $V_{s} / \mathbf{m m} / \mathbf{m i n}$ \\
\hline $400 \pm 10$ & 400 & 400 & $12: 1$ & 0.2 \\
\hline
\end{tabular}


Table 3. Processing parameters of the T6-DCT treatment.

\begin{tabular}{ccccccccc}
\hline \multirow{2}{*}{ Parameters } & \multirow{2}{*}{ Quenching } & \multicolumn{8}{c}{ Aging Treatment } \\
\cline { 3 - 10 } & & \multicolumn{2}{c}{ Cycle 1 } & \multicolumn{2}{c}{ Cycle 2 } & \multicolumn{2}{c}{ Cycle 3 } & Subsequent Aging \\
\hline Temperature $\left({ }^{\circ} \mathrm{C}\right)$ & 473 & -120 & 120 & -120 & 120 & -120 & 120 & 120 \\
\hline Time $(\mathrm{h})$ & 4 & 0.1 & 2 & 0.1 & 4 & 0.1 & 4 & 14 \\
\hline
\end{tabular}

The indirect-extrusion plate was machined into tensile specimens (gauge diameter: $6 \mathrm{~mm}$, gauge length: $25 \mathrm{~mm}$ ) in accordance with ASTM standard B557M-10. The tensile direction was parallel to the extrusion direction. Tensile tests were performed in triplicate at room temperature using a Shimadzu AG-X (Shimadzu, Tokyo, Japan) machine (100 kN, loading speed: $1 \mathrm{~mm} / \mathrm{min})$.

The grain morphology was examined via electron backscatter diffraction (EBSD; LEO-1450, Zeiss, Oberkochen, Germany) combined with scanning electron microscopy. Similarly, the precipitates were observed via transmission electron microscopy (TEM: JEM-1200EX, JEOL, Tokyo, Japan).

The segregation and distribution of the main atoms comprising the material were analyzed with a three-dimensional atom probe. Needle-shaped samples for atom probe tomography (APT) were prepared using a standard two-stage electro-polishing technique. APT was performed in a CAMECA LEAP 4000 HR (CAMECA Instruments, Madison, WI, USA) type local electrode atom probe at a temperature, pulse rate, and detector efficiency of $50 \mathrm{~K}, 200 \mathrm{kHz}$, and $36 \%$, respectively. Reconstruction and quantitative analysis of the APT data were performed with the IVASTM 3.6.12 software (CAMECA Instruments, Madison, WI, USA). The maximum separation method was used to select atomic clusters or precipitates in the needle-shaped samples. A separation distance (d) and minimum number of solute atoms in clusters $\left(\mathrm{N}_{\min }\right)$ of $0.5 \mathrm{~nm}$ and 10 , respectively, were used for the analysis.

\section{Experimental Results}

\subsection{Tensile Properties}

The tensile properties of indirectly extruded 7A99 ultra-high strength aluminum alloy subjected to T6 and T6-DCT treatments are shown in Table 4 and Figure 1 . An ultimate tensile strength $\sigma_{\mathrm{b}}$, tensile yield strength $\sigma_{0.2}$, and elongation $\delta_{5}$ of $705 \mathrm{MPa}, 678 \mathrm{MPa}$, and $14 \%$, respectively were realized via the T6-DCT treatment. These values were $6 \mathrm{MPa}$ (i.e., $1 \%$ ), $19 \mathrm{MPa}(3 \%$ ), and 3\% (i.e., $27 \%$ ) higher than the $\sigma_{\mathrm{b}}, \sigma_{0.2}$, and $\delta_{5}$, respectively, of the T6-treated samples. Therefore, the application of deep cryogenic treatment can simultaneously enhance the tensile strength, and (especially) the yield strength as well as elongation of the 7A99 aluminum alloy.

Table 4. Tensile properties of indirectly extruded 7A99 aluminum alloy plates subjected to T6 and T6-DCT processes.

\begin{tabular}{cccc}
\hline Heading & T6 & T6-DCT & Increasing Value \\
\hline UTS (MPa) & $699 \pm 0.8$ & $705 \pm 1$ & 6 \\
TYS (MPa) & $659 \pm 1.4$ & $678 \pm 1.6$ & 19 \\
Elongation $(\%)$ & $11 \pm 0.4$ & $14 \pm 0.6$ & 3 \\
\hline
\end{tabular}




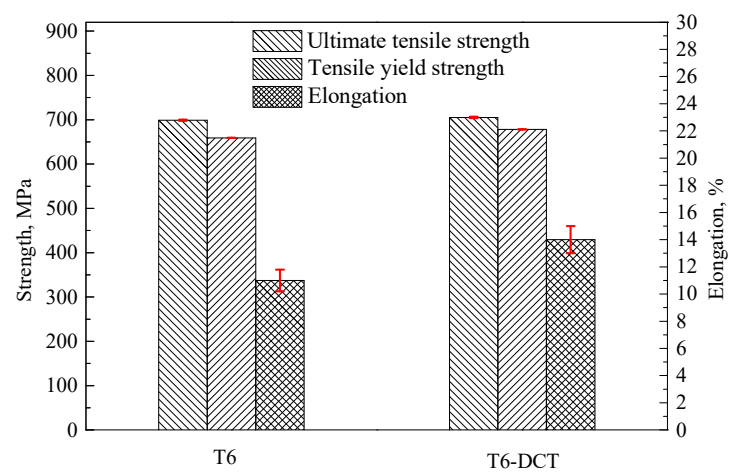

Figure 1. Tensile properties of indirectly extruded 7A99 aluminum alloy plates, subjected to T6 and T6-DCT treatments.

\subsection{Microstructures}

Figure 2 shows the EBSD images of indirectly extruded 7A99 aluminum alloy subjected to T6 and T6-DCT treatments. These two sets of samples are characterized by almost identical grain sizes and morphologies. Nevertheless, the grain size of the T6-DCT-treated alloy was slightly smaller and the distribution of microstructural morphology is more uniform than that of the T6-treated alloy.
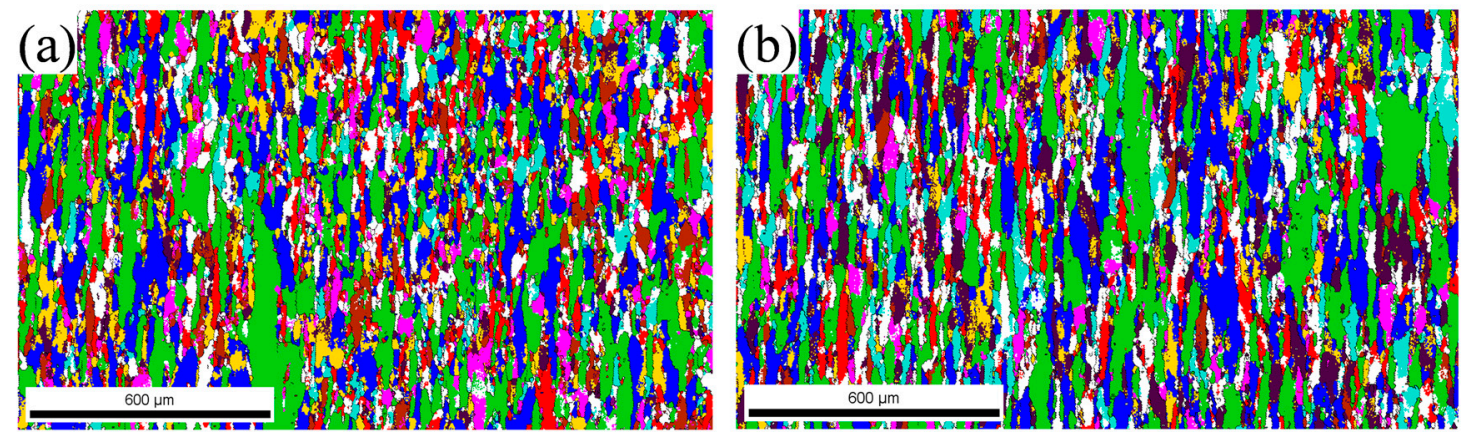

Figure 2. EBSD image of indirectly extruded 7A99 aluminum alloy plates subjected to T6 and T6-DCT reatments. (a) T6; (b) T6-DCT.

Figure 3 shows the TEM observations of the T6- and T6-DCT-treated 7A99 aluminum alloy. The precipitates were uniformly dispersed in the grains of the T6-treated alloy (Figure 3a) and the selected area electron diffraction (SAED) pattern indicates that the precipitation was mainly $\eta^{\prime}-\mathrm{MgZn}_{2}$ (zone axis was [001]). Figure $3 \mathrm{~b}$ reveals that, the average size of the precipitates along this direction decreased after the T6-DCT treatment, and the SAED pattern showed that the precipitates were mainly composed of $\eta^{\prime}-\mathrm{MgZn} \mathrm{n}_{2}$ and a small amount of the $\eta-\mathrm{MgZn}_{2}$ phase. The precipitates in the T6-DCT-treated alloy were more homogeneously distributed than those in the T6-treated alloy. The SAED pattern was bright and distinct, indicating that the number of precipitates increased, owing to the treatment. Therefore, DCT promotes the precipitation of $\eta^{\prime}-\mathrm{MgZn}_{2}$ and $\eta$ phases, refines the average size of the precipitates, and increases the uniformity of the microstructures. 

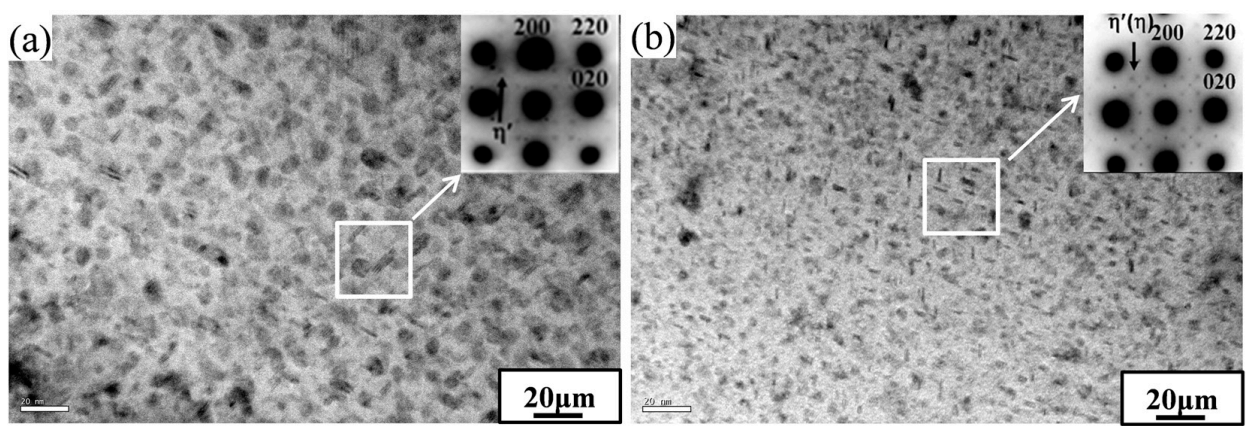

Figure 3. TEM images of the T6- and T6-DCT-treated 7A99 aluminum alloy (zone axis = [001]). (a) T6; and (b) T6-DCT.

\section{Discussion}

The aforementioned results indicate that the DCT process can accelerate the aging process. This results from the fact that the lattice is under compressive stress and some strain energy is stored in the materials when the temperature changes from room temperature to $-120^{\circ} \mathrm{C}$ during the DCT processes. When the samples are heated from low temperature to $120^{\circ} \mathrm{C}$ during the aging treatment, some of the stress is released in the process of thermal cycling. However, the residual stress remains in the crystal lattice, thereby acting as a driving force for aging and resulting in an accelerated aging process.

The effect of DCT on the aging behavior is further explored by using a Three-Dimensional Atom Probe (3DAP) technique to analyze the $\mathrm{Zn-}, \mathrm{Mg}$-, and $\mathrm{Cu}$-atom distributions associated with the $\mathrm{T} 6$ and T6-DCT processes.

As shown in Figure 4, the segregation degree of $\mathrm{Zn}, \mathrm{Mg}$, and $\mathrm{Cu}$ atoms in the matrix decreases significantly after the T6-DCT process. The number of small clusters increases, the number of large clusters decreases, and the uniformity of the microstructure improves. Similarly, the segregation of $\mathrm{Zn}$ and $\mathrm{Mg}$ elements is significantly reduced, and these elements almost overlap in some positions, indicating that the segregation degree of the corresponding $\eta^{\prime}-\mathrm{MgZn}_{2}$ and $\eta-M g Z n_{2}$ phases is synchronously reduced.

(a)

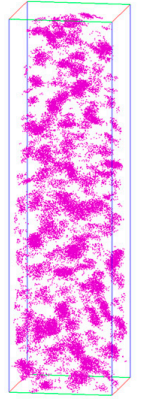

(e)

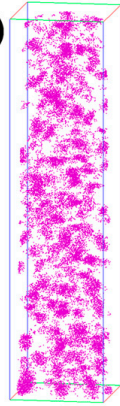

(b)

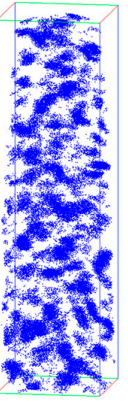

(f)

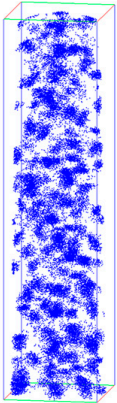

(c)

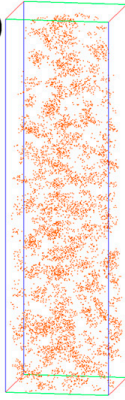

(g)

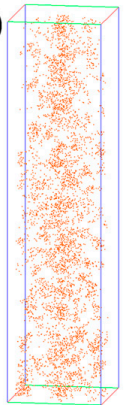

(d)

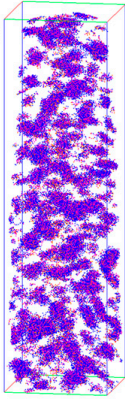

(h)

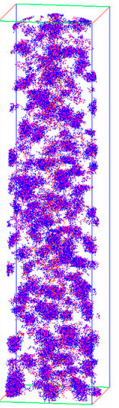

Figure 4. Distribution diagram of $\mathrm{Zn}, \mathrm{Mg}$, and $\mathrm{Cu}$ elements in T6- and T6-DCT-treated 7A99 alloy (a) Zn -T6; (b) Mg -T6; (c) Cu -T6; (d) Zn, Mg, and Cu -T6; (e) Zn T6-DCT; (f) Mg T6-DCT; (g) Cu T6-DCT; and (h) $\mathrm{Zn}, \mathrm{Mg}$, and $\mathrm{Cu}$ T6-DCT. 
The T6-DCT process leads to changes in the matrix, i.e., the fraction of $\mathrm{Zn}, \mathrm{Mg}$, and $\mathrm{Cu}$ atom clusters with sizes of (i) $10-20 \mathrm{~nm}$ increases significantly from $0.49 \%, 0.57 \%$, and $0.28 \%$ to $0.97 \%, 1.1 \%$, and $0.47 \%$, respectively (see Figure 5), (ii) $20-50 \mathrm{~nm}$ increases significantly from $0.38 \%, 0.38 \%$, and $0.16 \%$ to $0.42 \%, 0.42 \%$, and $0.17 \%$, respectively, and (iii) $>1000 \mathrm{~nm}$ decreases from $13.5 \%, 9.4 \%$, and $1.1 \%$ to $8.8 \%, 5.7 \%$, and $0.74 \%$, respectively. The results indicate that after T6-DCT, the number of small precipitates increases, whereas the number of large precipitates decreases, leading to the distribution of precipitates shown in Figure 4.
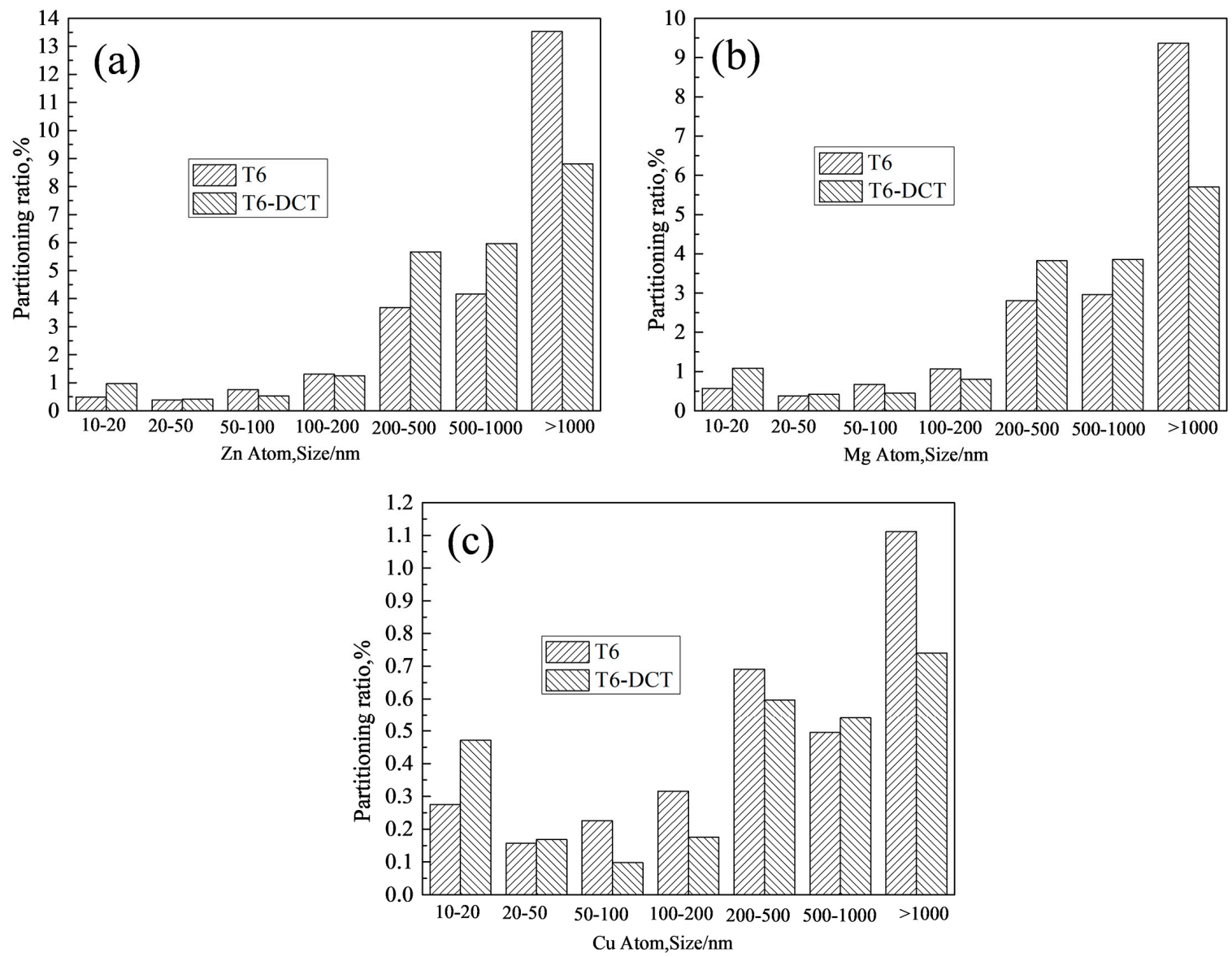

Figure 5. Size distribution of $\mathrm{Zn}, \mathrm{Mg}$, and $\mathrm{Cu}$ atom clusters in T6- and T6-DCT-treated 7A99 alloy. (a) Zn; (b) $\mathrm{Mg}$; and (c) Cu.

In summary, DCT improves the strength and ductility of the alloy mainly by accelerating precipitation, refining the size of the precipitates, and increasing the dispersion of the precipitates.

\section{Conclusions}

(1) The tensile strength, tensile yield strength, and elongation of the T6-DCT-treated 7A99 alloy are $6 \mathrm{MPa}, 19 \mathrm{MPa}$, and 3\% higher, respectively, than those of the T6-treated alloy.

(2) The grain size of the T6-DCT-treated 7A99 aluminum alloy is slightly smaller and more uniform than that of the T6-treated alloy. The matrix precipitates of the T6-DCT-treated alloy transform from a single phase $\left(\eta^{\prime}-\mathrm{MgZn}_{2}\right)$ into two phases $\left(\eta^{\prime}-\mathrm{MgZn}_{2}\right.$ and $\left.\eta-\mathrm{MgZn}_{2}\right)$. Compared with those in the T6-treated alloy, the precipitates are smaller and are more uniformly distributed.

(3) After the T6-DCT process, the segregation degree of $\mathrm{Zn}, \mathrm{Mg}$, and $\mathrm{Cu}$ elements decreases, the fraction of clusters with sizes of 10-20 nm and 20-50 nm increases, whereas the fraction of clusters with sizes of $>1000 \mathrm{~nm}$ decreases. 
(4) DCT accelerates the precipitation process, refines the precipitates, and increases the uniformity of the precipitate distribution, thereby resulting in improved strength and elongation of the T6-DC-treated 7A99 alloy.

Author Contributions: J.C. (Jianzhong Cui) and Z.L. conceived and designed the experiments; X.W. performed the experiments; J.C. (Junzhou Chen) analyzed the data; C.B. contributed eagents/materials/analysis tools; W.G. wrote the paper.

Funding: This work was supported by the National Key Research and Development Program of China (2016YFB0300901), the National Natural Science Foundation of China (U1708251, 51574075, U1608252), LiaoNing Revitalization Talents Program (XLYC1807027) and the Fundamental Research Funds for the Central Universities(N180905010).

Conflicts of Interest: The authors declare no conflict of interest.

\section{References}

1. Heinz, A.; Haszler, A.; Keidel, C.; Moldenhauer, S.; Benedictus, R.; Miller, W.S. Recent development in aluminum alloys for aerospace applications. Mater. Sci. Eng. A 2000, 280, 102-107. [CrossRef]

2. Chen, S.Y.; Chen, K.H.; Peng, G.S.; Chen, X.H.; Ceng, Q.H. Effect of heat treatment on hot deformation behavior and microstructure evolution of 7085 aluminum alloy. J. Alloys Compd. 2012, 537, 338-345. [CrossRef]

3. Zhang, X.M.; Tan, Q.; Liu, S.D.; Wu, Y.L.; Song, F.X.; Liu, X.X. Effect of quenching rate on aging behavior of 7085 aluminum alloy. Trans. Nonferrous Met. Soc. China 2014, 24, 870-877.

4. Liu, B.; Peng, C.Q.; Wang, R.C.; Wang, X.F.; Li, T.T. Recent development and prospects for giant plane aluminum alloys. Trans. Nonferrous Met. Soc. China 2010, 20, 1705-1715.

5. Warner, T. Recently-developed aluminum solutions for aerospace applications. Mater. Sci. Forum 2006, 519-521, 1271-1278. [CrossRef]

6. Nie, B.H.; Liu, P.Y.; Zhou, T.T. Effect of compositions on the quenching sensitivity of 7050 and 7085 alloys. Mater. Sci. Eng. A 2016, 667, 106-107. [CrossRef]

7. Liu, S.D.; Li, C.B.; Han, S.Q.; Deng, Y.L.; Zhang, X.M. Effect of natural aging on quench-induced inhomogeneity of microstructure and hardness in high strength 7055 aluminum alloy. Mater. Sci. Eng. A 2015, 625, 34-35. [CrossRef]

8. Yu, H.C.; Wang, M.P.; Sheng, X.F.; Li, Z.; Chen, L.B.; Lei, Q.; Chen, C.; Jia, Y.L.; Xiao, Z.; Chen, W.; et al. Microstructure and tensile properties of large-size 7055 aluminum billets fabricated by spray forming rapid solidification technology. J. Alloys Compd. 2013, 578, 208-214. [CrossRef]

9. Xie, X.; Wu, X.C.; Min, N.; Shen, Y.L. Carbon Segregation Behavior of high carbon high-alloy steel during deep cryogenic treatment using 3DAP. Acta Metall. Sin. 2015, 3, 325-326.

10. Wang, J.; Fu, R.D.; Li, Y.J.; Zhang, J.F. Effects of deep cryogenic treatment and low-temperature aging on the mechanical properties of friction-stir-welded joints of 2024-T351 aluminum alloy. Mater. Sci. Eng. A 2014, 609, 147-148. [CrossRef]

11. Wu, H.Y.; Ai, Z.R.; Liu, X.H. Progress of research and application on cryogenic treatment of steels. Trans. Mater. Heat Treat. 2013, 34, 1-6.

12. Wang, K.K.; Tan, Z.L.; Gu, K.X.; Gao, B.; Gao, G.H.; Misra, R.D.K.; Bai, B.Z. Effect of deep cryogenic treatment on structure-property relationship in an ultrahigh strength $\mathrm{Mn}-\mathrm{Si}$-Cr bainite/martensite multiphase rail steel. Mater. Sci. Eng. A 2017, 684, 559-566. [CrossRef]

13. Li, H.Z.; Tong, W.P.; Cui, J.J.; Zhang, H.; Chen, L.Q.; Zuo, L. The influence of deep cryogenic treatment on the properties of high-vanadium alloy steel. Mater. Sci. Eng. A 2016, 662, 356-362. [CrossRef]

14. Li, G.R.; Wang, H.M.; Yan, X.T.; Cai, Y.; Zhao, Y.T.; Wang, J.J. Structure evolution and properties of 7055Aluminum alloy with cycle cryogenic treatment. Rare Met. Mater. Eng. 2013, 42, 251-254.

15. Chen, D.; Li, W.X. Cryogenic treatment of $\mathrm{Al}$ and $\mathrm{Al}$ alloys. Trans. Nonferrous Met. Soc. China 2000, 10, 891-895.

16. Asl, K.M.; Tari, A.; Khomamizadeh, F. Effect of deep cryogenic treatment on microstructure, creep and wear behaviors of AZ91 magnesium alloy. Mater. Sci. Eng. A 2009, 523, 27-31. [CrossRef]

(C) 2019 by the authors. Licensee MDPI, Basel, Switzerland. This article is an open access article distributed under the terms and conditions of the Creative Commons Attribution (CC BY) license (http://creativecommons.org/licenses/by/4.0/). 